\title{
SOSIALISASI PENGGUNAAN AKUN MARKETPLACE BAGI USAHA KECIL DI CEMANDI SERTA PEMASANGAN PAPAN NAMA JALAN DI SEPANJANG, SIDOARJO, JAWA TIMUR
}

\author{
Stephanie Astrid Ayu ${ }^{1}$, Martina Ningtyas ${ }^{2}$ \\ ${ }^{1,2}$ Universitas Katolik Darma Cendika

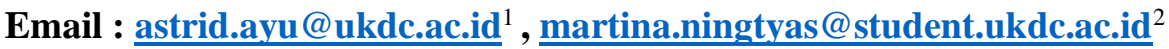

\begin{abstract}
Abstrak
Program Pengabdian Masyarakat merupakan salah satu program kerja mahasiswa sebagai sarana pembelajaran dalam mengimplementasikan keterampilan untuk hidup bermasyarakat. Program kerja Pengabdian Masyarakat merupakan program wajib yang diselenggarakan oleh Universitas. Melalui program kerja Pengabdian Masyarakat, diharapkan mahasiswa dapat mengelola dan bekerja sama dengan semua unit terkait dalam upaya mewujudkan program kerja yang bermanfaat bagi masyarakat di tempat terselenggaranya program Pengabdian Masyarakat. Kondisi pandemic Covid-19 berdampak pada perubahan sistem dalam pelaksanaan program pengabdian masyarakat. Program kerja kelompok 7 UKDC dilaksanakan di 2 lokasi. Lokasi ditentukan dengan berdasarkan pada jarak lokasi yang tidak terlalu jauh dari tempat tinggal anggota kelompok Pengabdian Masyarakat. Lokasi Pengabdian Masyarakat Kelompok 7 berada di lingkungan Perumahan Griya Kartika Cemandi Kecamatan Sedati dan di Gang Cendraw asih RT 09 RW 06 Sepanjang, Kecamatan Taman, Sidoarjo.Program kerja pengabdian masyarakat ini bertujuan untuk membantu warga Griya Kartika dalam memasarkan dan mengelola usaha warga dalam bidang kuliner dengan memanfaatkan akun marketplace yang saat ini menjadi trend dalam dunia perkulineran. Program kerja di lokasi yang kedua, yaitu di Gang Cendrawasih RT 09 RW 06 Sepanjang, Kecamatan Taman, Sidoarjo adalah membantu warga dalam pembuatan papan nama jalan serta papan nomor rumah dalam rangka upaya mewujudkan manajemen tata kelola lingkungan tinggal warga. Program pengabdian masyarakat ini dilakukan dalam 3 tahapan yaitu tahapan awal, tahapan proses dan tahapan akhir. Tahapan awal dilakukan dengan melakukan kunjungan ke rumah warga RT 22 RW 05 Griya Kartika dan RT 09 RW 06 Sepanjang. Untuk tahapan proses dilaksanakan mulai dari pendataan warga di Griya Kartika untuk pembuatan akun marketplace serta pendataan rumah warga di RT 09 RW 06 Sepanjang terutama rumah warga yang belum memiliki nomor rumah. Selanjutnya proses pelaksaanaan pembuatan akun marketplace dan pembuatan serta pemasangan papan nama jalan dan nomor rumah di RT 09 RW 06 Sepanjang.

Kata Kunci : Marketplace, Usaha Kecil, Papan Nama
\end{abstract}

\begin{abstract}
Community Service Program is one of the student work programs to learn in implementing skills for community life. The Community Service work program is a mandatory program organized by the University. Through the Community Service work program, it is expected that students can manage and cooperate with all relevant units to realize a work program that benefits the community in the community service program. The condition of the Covid-19 pandemic has an impact on system changes in the implementation of community service programs. The group 7 UKDC work program is conducted in 2 locations. The location is determined based on the distance of the location that is not too far from the residence of the Community Service group members. Community Service Location Group 7 is in Griya
\end{abstract}


Kartika Cemandi Housing Sedati Subdistrict and Gang Cendrawasih RT 09 RW 06 Sepanjang, Taman Subdistrict, Sidoarjo.This community service work program aims to help griya Kartika residents in marketing and to manage the business of citizens in the culinary field by utilizing marketplace accounts that are currently a trend in the world of Foods. The work program in the second location, namely in Gang Cendrawasih RT 09 RW 06 Sepanjang, Taman Subdistrict, Sidoarjo, assists residents in creating street signage and house number boards order to realize the management of environmental governance of residents. This community service program is conducted in 3 stages: the initial, process, and final stages. The initial stage was done by visiting the homes of residents of RT 22 RW 05 Griya Kartika and RT 09 RW 06 Sepanjang. The stage of the process is carried out starting from the data collection of residents in Griya Kartika for the creation of marketplace accounts and the data collection of people's homes in RT 09 RW 06 Along especially the homes of residents who do not have a home number. Furthermore, implementing the creation of marketplace accounts and creating and installing street signage and house numbers in RT 09 RW 06 Sepanjang.

Keywords: Marketplace, Small Business, Signage 


\section{PENDAHULUAN}

Gambaran situasi lokasi untuk pembuatan akun marketplace di Perumahan Griya Kartika Cemandi didominasi oleh warga usia produktif dengan profesi kaum Bapak sebagai anggota TNI (Tentara Nasional Indonesia), dosen dan beberapa sebagai karyawan. Selain itu beberapa warga berusaha untuk mendukung perekonomian keluarga dengan berjualan makanan. Pada dasarnya warga berjualan dengan sistem dan metode konvensional, yaitu dengan membuat daftar menu dalam spanduk, memasarkan menu masakan melalui platform whatsapp, membuat poster sederhana, dan melalui informasi dari mulut ke mulut. Gambaran situasi lokasi kedua bertempat di RT 09 RW 06 Sepanjang Taman Sidoarjo, warga di lingkungan ini sebagian besar menjalankan roda perekonomian dengan berwiraswasta. Situasi jalan lingkungan tinggall tanpa nama serta rumah warga yang tanpa nomor rumah membuat tamu atau pengunjung mengalami kesulitan dalam mencari rumah yang dituju. Banyak kurir juga mengalami kesulitan menemukan rumah penerima paket yang akan dikirimkan.

Berdasarkan hasil analisa dan wawancara yang dilakukan oleh kelompok 7 Pengabdian Masyarakat, diperoleh informasi bahwa saat ini hasil penjualan para pengusaha kuliner warga Griya Kartika Cemandi belum optimal. Harapan warga dengan adanya pembuatan akun marketplace akan mampu meningkatkan jumlah penjualan sehingga berdampak pada bertambahnya keuntungan yang diperoleh dari penjualan makanan. Saat ini warga masih belum memiliki pengetahuan tentang akun marketplace yang bisa digunakan sebagai sarana pendukung promosi penjualan secara online. Pembuatan akun marketplace tersebut merupakan hal yang baru bagi warga Griya Kartika Cemandi, melalui program pengabdian masyarakat ini Kelompok 7 membantu warga memberikan edukasi dan informasi yang diperlukan sampai dengan membantu proses pembuatan akun marketplace untuk warga. Sedangkan permasalahan di lokasi keduaRT 09 RW 06 Sepanjang adalah tidak tersedianya papan nama jalan dan papan nomor rumah warga RT 09 RW 06 Kelurahan Sepanjang, Kecamatan Taman, Kabupaten Sidoarjo menyebabkan kesulitan bagi pengunjung luar daerah mencari alamat yang dituju.

Tujuan dari program pengabdian masyarakat kelompok 7 ini adalah :

1. Membantu warga Griya Kartika dalam pembuatan akun marketplace 
2. Membantu warga RT 09 RW 06 Sepanjang dalam pembuatan papan nama jalan, dan nomor rumah

\section{METODE}

Pelaksanaan Program pengabdian masyarakat kelompok 7 ini dimulai sejak bulan Februari 2021 dan telah selesai pada bulan Mei 2021. Tahapan kegiatan yang dilakukan oleh kelompok 7 dalam program kegiatan pengabdian masyarakat di Griya Kartika serta di RT 09 RW 06 Sepanjang adalah sebagai berikut

a. Pembekalan dan penentuan tujuan lokasi program pengabdian masyarakat.

Lokasi program pengabdian masyarakat kelompok 7 di lakukan di Griya Kartika Kecamatan Cemandi Kelurahan Sedati Kabupaten Sidoarjo dan RT 09 RW 06 Kecamatan Sepanjang Kelurahan Taman Kabupaten Sidoarjo. Berikut gambar lokasi daerah yang diambil dari google map:

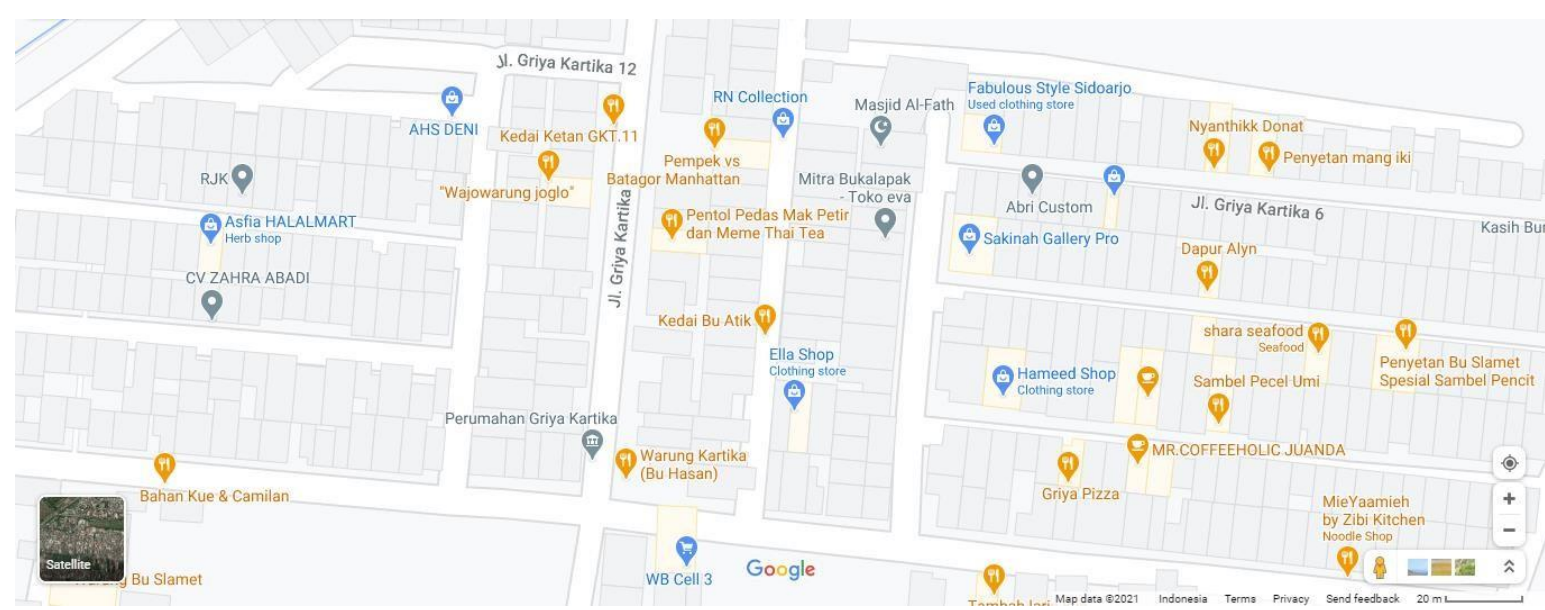

Gambar 1. Perumahan Griya Kartika Cemandi 


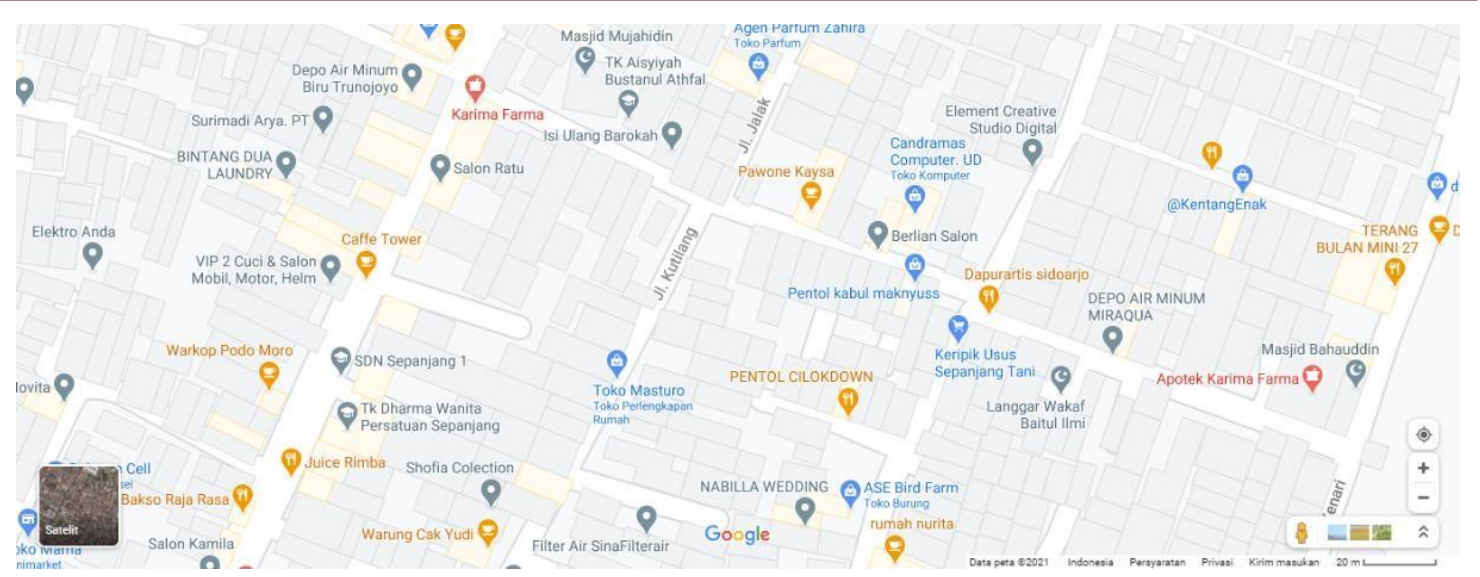

Gambar 2. RT 09 RW 06 Sepanjang Sidoarjo

b. Melakukan survei lokasi kegiatan Program Pengabdian Masyarakat Kelompok 7. Survei lokasi dan kunjungan dilakukan oleh perwakilan anggota Kelompok 7. Kunjungan ini bertujuan untuk bersilaturahmi dengan perwakilan warga serta melakukan wawancara dan mencari informasi tentang situasi dan kondisi lingkungan sekitar pelaksanaan program Pengabdian Masyarakat. Jadwal pelaksanaan survei ini serentak dilakukan di dua lokasi, mengingat hanya perwakilan kelompok yang melakukan kunjungan, maka waktu pelaksanaan bisa bersama-sama. Hal ini dilakukan dalam rangka memenuhi salah satu protokol kesehatan, yaitu menghindari kerumunan. Pelaksanaan survey lokasi juga menggunakan protokol kesehatan lengkap, yaitu menggunakan masker, tidak berjabat tangan, serta menjaga jarak.

c. Melakukan analisa sosial di Griya Kartika dan RT 09 RW 06 Sepanjang Analisa sosial dilakukan di RT 22 RW 05 Griya Kartika serta di RT 09 RW 06 Sepanjang. Analisa sosial dilakukan agar kelompok 7 mengetahui tentang keadaan geografis, kedaan lingkungan, kondisi sosial dan ekonomi, kegiatan masyarakat serta permasalahan yang di hadapi oleh warga Griya Kartika dan warga di RT 09 RW 06 Sepanjang. Sambil melakukan koordinasi lebih lanjut untuk perencanaan program kerja yang akan dilaksanakan.

d. Tahap pelaksanaan program kerja Pengabdian Masyarakat Tahap pertama yaitu dengan melakukan kunjungan ke rumah warga untuk mendata serta membantu dalam proses pembuatan akun marketplace. Tahap kedua menghitung dan 
mendata warga gang Cendrawasih yang belum terpasang nomor rumah. Tahap ketiga melakukan wawancara dengan beberapa warga mengenai kesulitan penjualan yang di hadapi karena adanya pandemi ini.

e. Proses realisasi program kerja Pengabdian Masyarakat Kelompok 7

Realisasi kegiatan program pengabdian masyarakat berupa pembuatan akun marketplace dilakukan dengan sistem door to door. Kelompok 7 datang kerumah warga untuk membantu membuat akun marketplace. Proses pembuatan akum marketplace dimulai dengan proses download dan instal aplikasi marketplacae ke smartphone calon pemilik akun, kemudian proses pendaftaran dan pembuatan akun sesuai dengan data diri pemilik akun yang akan di daftarkan. Langkah selanjutnya adalah memandu calon pemilik akun tersebut melengkapi data dan syarat pembuatan akun. Proses pembuatan akun selesai sampai dengan akun tersebut telah terverifikasi dan siap digunakan. Tahap berikutnya adalah memberikan informasi dan edukasi kepada warga pengguna akun tersebut bagaimana cara mengoperasikan dan manfaat yang diperoleh dengan adanya akun tersebut.

f. Realisasi Program Pembuatan dan Pemasangan Papan Nama Jalan dan Nomor Rumah Tahap awal pembuatan papan nama jalan dan nomor rumah warga dimulai dengan pemilihan desain bersama dengan Bapak Ketua RT. Sesuai dengan kesepakatan dari Bapak Ketua RT dan perwakilan warga, maka Kelompok 7 melakukan perbaikan desaian dan kemudian melakukan pemesanan papan nama jalan tersebut melalui platform shopee. Papan nama jalan dan nomor rumah warga tersebut selesai dipesan dalam kurun waktu tidak lama, proses pembuatan dan pengiriman kurang lebih satu minggu. Setelah dilakukan pemeriksaan untuk menghindari kesalahan penulisan nama dan nomor, papan nama dan nomor rumah warga tersebut diserahkan kepada Bapak Ketua RT. Tahap selanjutnya adalah proses pemasangan papan nama jalan serta nomor rumah warga yang didampingi serta dalam pengawasan ketua RT 09 RW 06 Sepanjang. Beberapa warga juga ikut serta membantu proses pemasangan papan nama jalan dan nomor rumah tersebut. Berikut desain untuk papan nama jalan di RT 09 RW 06 Sepanjang. 


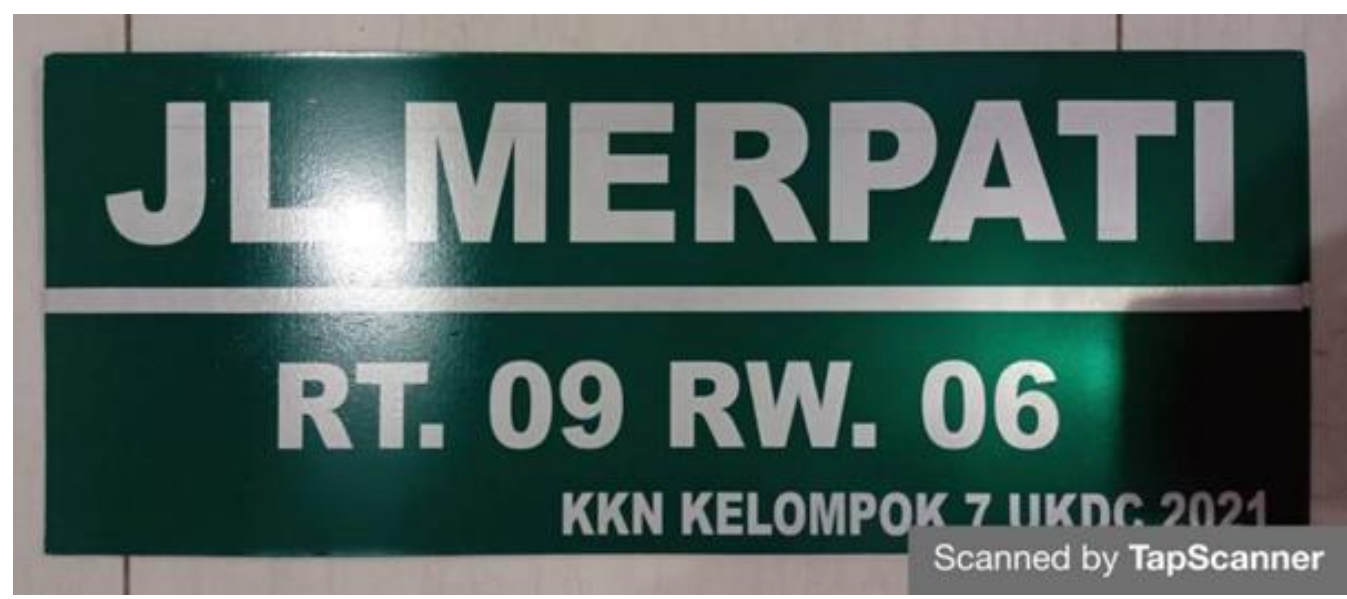

Gambar 3. Desain papan nama jalan di RT 09 RW 06 Sepanjang

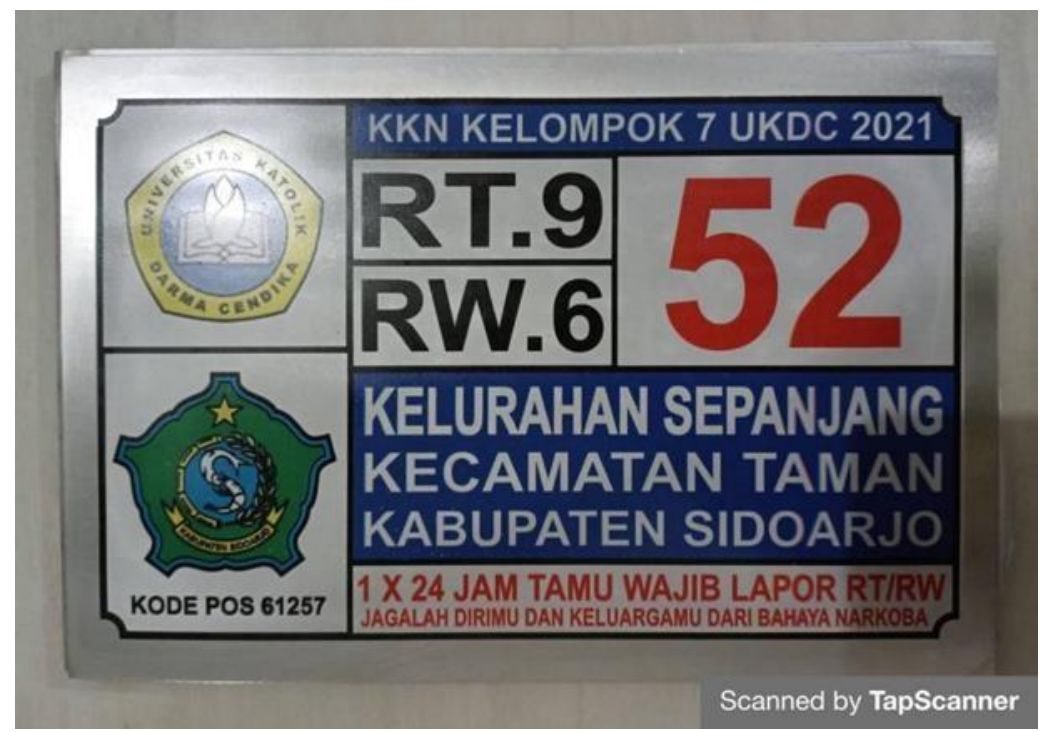

Gambar 4. Desain papan nomor rumah di RT 09 RW 06 Sepanjang

\section{HASIL DAN PEMBAHASAN}

Program kerja Pengabdian Masyarakat Kelompok 7 bertujuan untuk membantu warga mengelola dan memasarkan usaha dalam bidang kuliner guna menunjang dan memenuhi kebutuhan ekonomi harian. Warga Griya Kartika Cemandi saat ini memasarkan dan mempromosikan usaha kuliner dengan cara konvensional. Melalui program pengabdian masyarakat ini Kelompok 7 memberikan edukasi dan informasi yang bermanfaat bagi para 
pengusaha kuliner Griya Kartika Cemandi. Penjualan dan pemasaran dengan cara konvensional dipandang belum memberikan hasil yang memuaskan. Melalui metode pembuatan akun marketplace diharapkan penjualan dan pemasaran usaha kuliner yang dijalankan dapat meningkatkan jumlah penjualan serta mampu memberikan keuntungan yang lebih besar. Hal ini disebabkan karena dengan adanya akun marketplace kemungkinan akan dapat menambah jumlah pelanggan dan memperluas area operasional pesanan.

Proses pendataan warga dilakukan di kediaman RT 22 RW 05 Griya Kartika dan melakukan kunjungan secara door to door kerumah warga Griya Kartika untuk wawancara dengan warga mengenai kondisi serta permasalahan yang di hadapi dalam mempromosikan usaha kuliner.

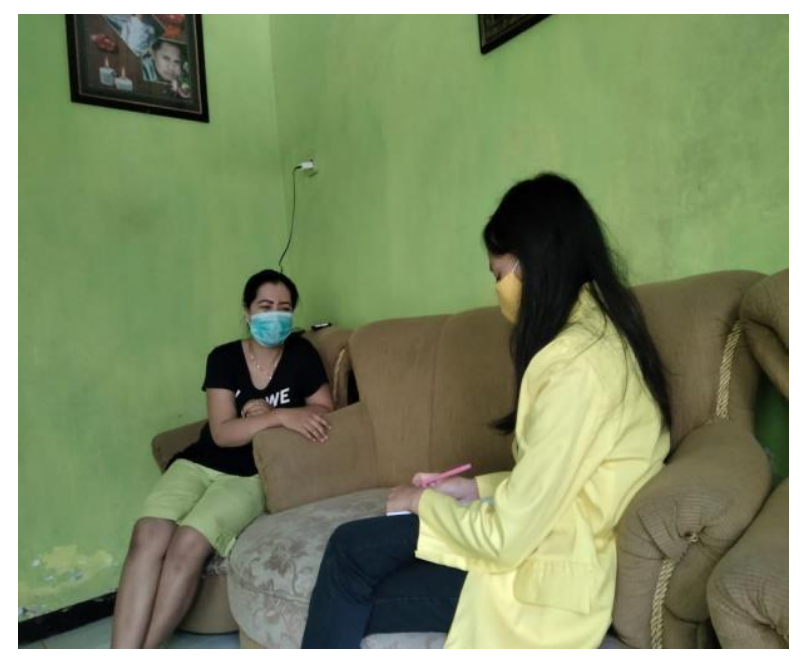

Gambar 5. Melakukan pendataan terkait pembuatan akun marketplace di Griya Kartika

Pendataan warga dilakukan dengan memenuhi protokol kesehatan, yaitu dengan menggunakan masker, mencuci tangan, menjaga jarak, dan menjauhi kerumunan. Pendataan dilakukan untuk memperoleh informasi penting berkaitan dengan pendaftaran dan pembuatan akun marketplace. 


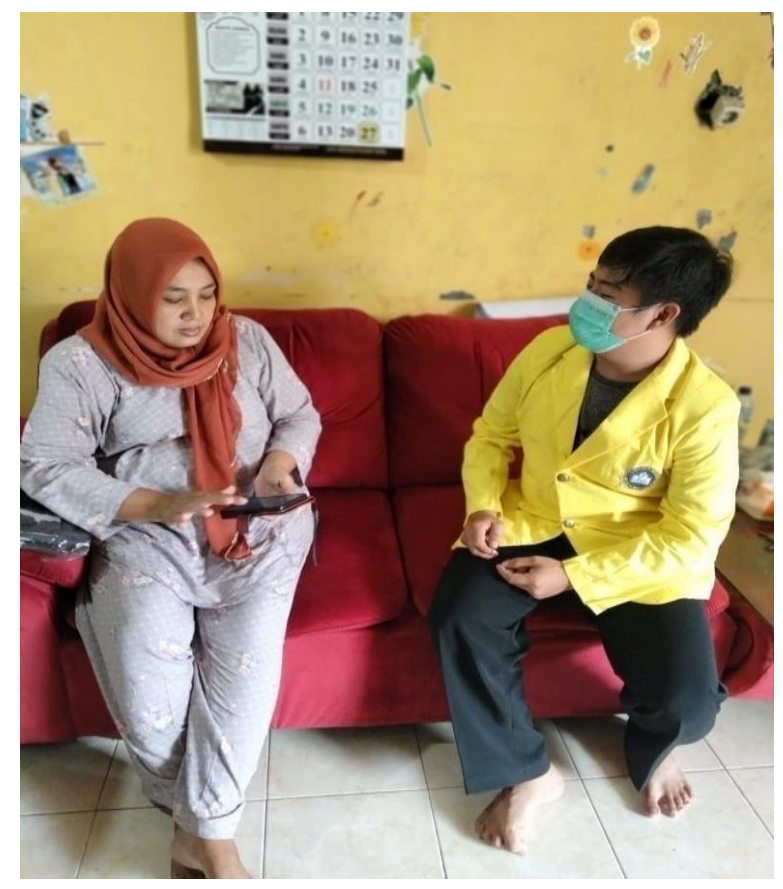

Gambar 6. Membantu warga Griya Kartika dalam pembuatan akun marketplace

Di sisi lain kelompok 7 juga melakukan tinjauan lokasi untuk mengetahui keadaan lokasi sekitar baik dari segi geografis, kondisi lingkungan hingga kegiatan masyarakat di Griya Kartika. Akun marketplace ini berguna untuk mempromosikan produk warga Griya Kartika yang mengalami penurunan penjualan dikarenakan pandemi. E-Commerce sendiri menurut C.Laudon dan P. Laudon dalam Wahyuni 2018 adalah proses jual beli yang sudah terkomputerisasi menggunakan jaringan internet dan media digital lainnya. Sedangkan marketplace menurut Apriadi 2017 dalam Wahyuni 2018 adalah sebuah media yang mewadahi transaksi jual beli secara online agar bisa melakukan proses transaksi. Marketplace ini sangat berguna untuk usaha kecil menengah karena penjual tidak harus memiliki toko secara nyata, penjual hanya perlu mendaftar di akun marketplace agar bisa berjualan. Tetapi dalam marketplace penjual harus meningkatkan kualitas produk serta pelayanan agar bisa meningkatkan penjualan (Wahyuni 2018). 
Program kerja kedua, yaitu pemasangan papan nama jalan dan nomor rumah warga Gang Cendrawasih, Sepanjang. Program ini bertujuan membantu menciptakan tata kelola daerah dan memberikan manfaat bagi warga sekitar. Pemasangan papan jalan akan memudahkan proses pencarian alamat tujuan bagi tamu, pengunjung atau kurir yang mengirimkan paket. Begitu pula halnya dengan pemasangan nomor rumah warga, akan memudahkan pencarian alamat warga yang dituju sehingga proses pencarian alamat tujuan bisa dilakukan dengan cepat dan tepat. Secara tidak langsung program ini juga bermanfaat dalam memudahkan pendataan jumlah warga.

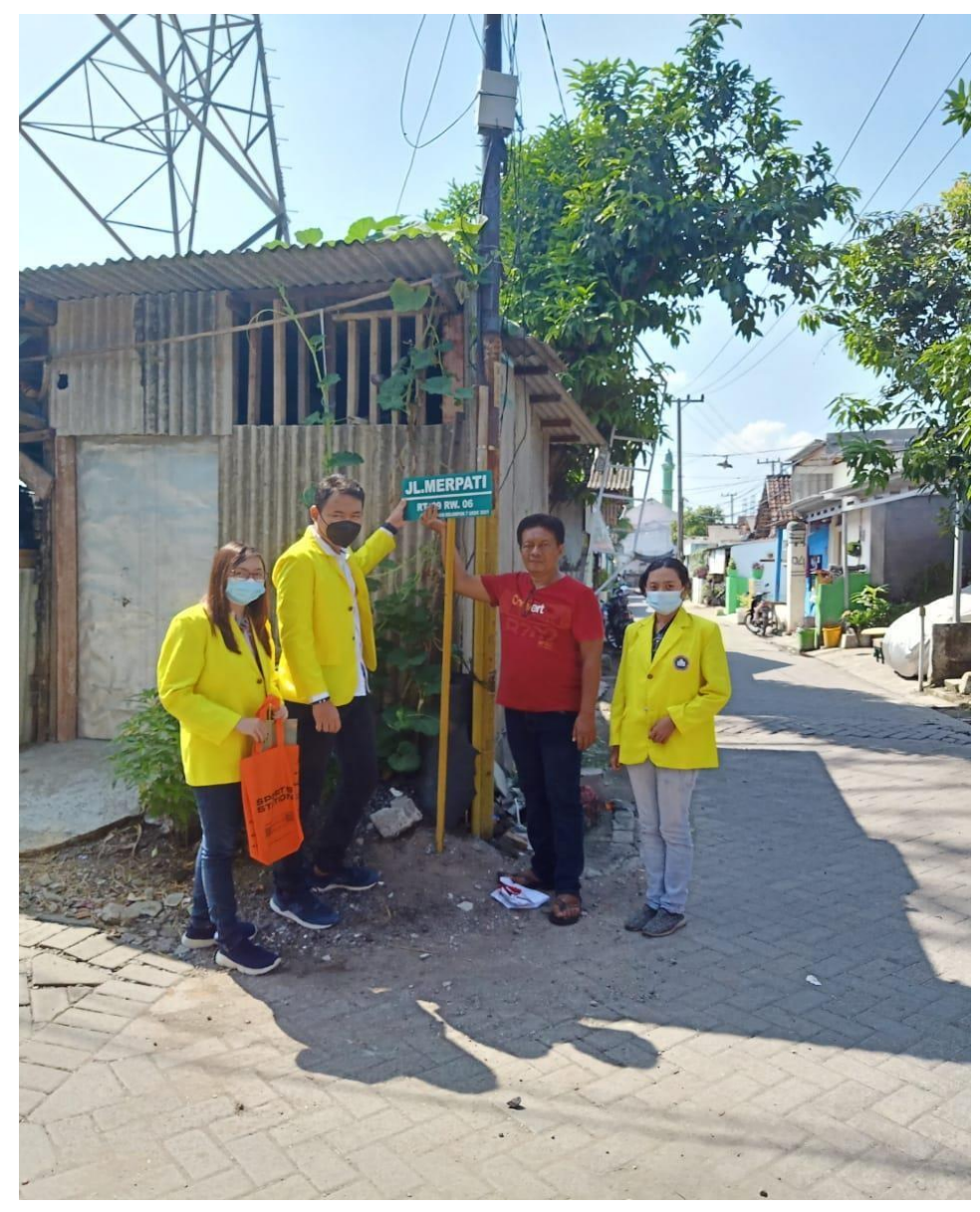

Gambar 7. Pemasangan papan nama jalan di RT 09 RW 06 Sepanjang 


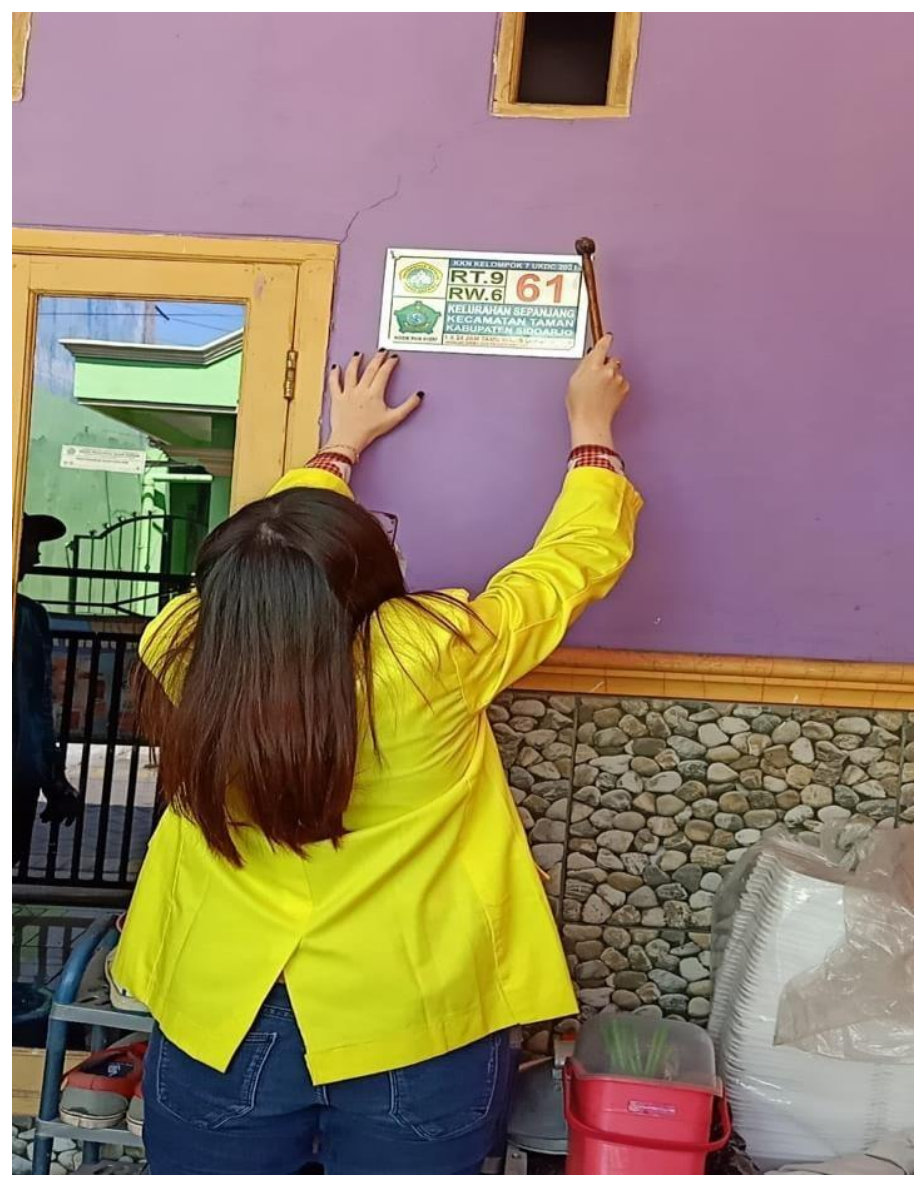

Gambar 8. Pemasangan papan nomor rumah di RT 09 RW 06 Sepanjang

Sebelum memasang papan nama jalan dan penomoran rumah di RT 09 RW 06 Sepanjang kelompok 7 membeli perlengkapan seperti paku beton, paku kawat dan barang barang lain yang dibutuhkan. Pemasangan papan nama jalan dan penomoran rumah ini dibantu oleh RT 09 serta warga setempat dalam pelaksanaannya. Setelah selesai kelompok 7 melakukan foto bersama dengan RT 09 RW 06 Sepanjang. Menurut sinergimedia.co.id (2019) papan nama jalan berfungsi agar orang dari luar daerah tersebut mengetahui tentang keberadaan mereka sehingga papan nama jalan akan membantu agar masyarakat dari luar daerah tidak tersesat pada saat mencari alamat yang dituju. Sedangkan penomoran rumah bertujuan agar melengkapi sistem informasi agar warga dari luar daerah Sepanjang bisa mengetahui tentang jelas alamat nomor rumah warga yang berada di Sepanjang khususnya RT 09 RW 06 Sepanjang. 
Melalui program kerja pengabdian masyarakat oleh Kelompok 7 berupa pembuatan akun marketplace serta pembuatan papan nama jalan dan papan nomor rumah ini maka diharapkan terjadi perubahan yang bermanfaat bagi warga Griya Kartika serta warga RT 09 RW 06 Sepanjang yaitu :

1. akun marketplace bisa membantu warga dalam mempromosikan usaha kulinernya serta bisa membantu meningkatkan perekonomian warga Griya Kartika

2. Solusi bagi warga setempat maupun pendatang dalam menemukan alamat yang dituju dan memberikan kemudahan dalam sensus kependudukan.

\section{KESIMPULAN}

Berdasarkan hasil dari kegiatan Pengabdian Masyarakat Kelompok 7 yang telah dilaksanakan ini dapat diambil kesimpulan sebagai berikut :

a. Proses edukasi dan pembuatan akun marketplace mulai dari awal hingga tahap akhir dibuktikan dengan akun yang telah dibuat dan siap digunakan oleh warga Griya Kartika Cemandi, Sidoarjo

b. Telah terealisasinya pemasangan papan nama jalan, dan penomoran di setiap rumah warga RT 09 RW 06 Sepanjang

\section{DAFTAR PUSTAKA}

ARIFUDIN, O. (2020). PKM PEMBUATAN KEMASAN, PENINGKATAN PRODUKSI DAN PERLUASAN PEMASARAN KERIPIK SINGKONG DI SUBANG JAWA BARAT. INTEGRITAS : Jurnal Pengabdian, 4(1), 21. doi:10.36841/integritas.v4i1.514

CILEGON https://jurnal.untirta.ac.id/index.php/Dinamika/article/download/8751/5830

Elburdah, R. P., Haryoko, U. B., Septiani, F., Maduningtias, L., \& Krisyanto, E. (2020). PENYULUHAN MANAJEMEN PEMASARAN YANG STRATEGIS DALAM PENGEMBANGAN YAYASAN NURUL IKHSAN. DEDIKASI PKM, 1(1), 121. doi:10.32493/dedikasipkm.v1i1.6067

Fitriyana, F., Nuryani, A., Rosyati, T., \& Gusvia, Y. (2021). PELATIHAN PEMANFAATAN MARKETPLACE PADA UMKM DALAM MASA COVID-19. DEDIKASI PKM, 2(2), 206. doi:10.32493/dedikasipkm.v2i2.9765

Gampong Yub mee KKN Unsyiah p279 Penomoran rumah warga diakses pada 20.05.2021 http://webblogkkn.unsyiah.ac.id/yubmee9/program-kelompok/bidangpembangunan/penomoranrumah-warga/

Hayati, F. A., Asmalah, L., Arianto, N., Kencana, P. N., \& Noviyanti, I. (2020). PELATIHAN 
MANAJEMEN PEMASARAN DIGITAL PADA WARGA BELAJAR PKBM INSAN KARYA. DEDIKASI PKM, 1(3), 62. doi:10.32493/dedikasipkm.v1i3.6688

Hendra, D., Merati, A., Aprilliani, S., Afandi, M. F., \& Nardiono, N. (2020). PERANCANGAN DAN PENERAPAN E-MARKETPLACE UNTUK USAHA KECIL DAN MENENGAH PADA LEMBAGA PEMBERDAYAAN MASYARAKAT KELURAHAN DEPOK JAYA. DEDIKASI PKM, 1(1), 60. doi:10.32493/dedikasipkm.v1i1.6056

Media Sinergi fungsi dan tips membuat plang nama jalan July,16 2019 diakses pada 17.05.2021 https://sinergimedia.co.id/plang-nama-jalan/

Nora Pitri Nainggolan, \& Intan Utna Sari. (2020). PEMBINAAN DAN PENERAPAN STRATEGI PEMASARAN MELALUI MEDIA SOSIAL PADA HOME INDUSTRI MASYARAKAT TANJUNG GUNDAP. Jurnal Abdimas Bina Bangsa, 1(2), 267-275. doi:10.46306/jabb.v1i2.31

Puspaningtyas, A., \& Halik, A. (2020). PKM Pengembangan Sumberdaya Manusia untuk Pemasaran Online Usaha Kecil Menengah “Kedurus Sejahtera” Surabaya. Society, 1(1), 1417. doi:10.37802/society.v1i1.90

Wahyuni Nuraida, Ade Irman Saeful Mutaqin, Akbar Gunawan PENGENALAN DAN PEMANFAATAN MARKETPLACE E-COMMERCE UNTUK PELAKU UKM WILAYAH

Zulkarnain, I., Setiawan, T. H., Syamtoro, B., Nurhamdi, M., \& Octaviani, I. S. (2020). PENERAPAN DIGITAL MARKETING SEBAGAI STRATEGI KOMUNIKASI PEMASARAN USAHA KECIL DAN MENENGAH WARGA DEPOK JAYA. DEDIKASI PKM, 1(1), 86. doi:10.32493/dedikasipkm.v1i1.6060 